\title{
BULLYING AND CYBERBULLYING
}

By Dr. Elizabeth Englander

Harvard Education Press, 2013

\section{Introduction: The Bullying Enigma}

Just hit him back, and he'll leave you alone.

Hit him back, and you'll be suspended for hitting.

We want kids to always report to us when bullying is happening. But don't tattle.

Adults must always intervene in bullying cases.

Why can't kids learn to deal with any of these problems by themselves?

This may not be the first book about bullying that you've picked up. Perhaps you've dipped into many articles or books, but like many educators, you still feel frustrated with a problem that seems to stubbornly defy a tsunami of opinions, discussions, stories, and proposed solutions. Anyone working in schools knows very well how serious bullying can be; on the other hand, it's not uncommon to hear even mild slights characterized as bullying. We want to help children who are being targeted, but we also know that there's no way to require children to like each other. We know that children can be cruel online, but realistically, how can educators address problems that are happening off campus and in cyberspace?

Everyone seems to agree that bullying has always existed. That fact alone can make it hard to understand why this problem sometimes feels as though it's spinning out of control. It's always been here-yet now it's also different. We know that referring to everything and anything as bullying isn't correct; but it's hard to say what bullying is, exactly. A teacher told me once that he felt like he was trying to clutch Jell-O. The problem is real - and serious - but we're having trouble getting a grip on it.

My purpose in this book is to help educators sort through the thorny issues that complicate our efforts to understand bullying and cyberbullying, and to suggest practical and realistic ways to address these behaviors effectively. Despite the plethora of publications in this field - many of which offer valuable insights according to their different areas of emphasis - I've been struck by how unusual it is to find approaches that are both concrete and genuine but that also cover the entire spectrum of online and offline bullying behaviors. I don't think these social problems between children can be addressed without a solid understanding of child development, how children actually bully today, what goes on in schools, and how digital behaviors emerge during childhood and interrelate with (and sometimes determine) in-school socializing. Bullying is a complex puzzle because solving it needs all of these pieces. And that's exactly the perspective that I present in this book.

Let me introduce myself by saying I'm not a college professor, or a professional trainer in bullying prevention, or a researcher in bullying and cyberbullying, or a parent of three kids (two teens), or a teacher. I'm all of those things. And each role I play adds an important skill and dimension to the mix. First and foremost, I'm a professor of psychology at a state university in Massachusetts. At that university, I run a center (the 
Massachusetts Aggression Reduction Center, or MARC) where I (with my colleagues and students) conduct research into bullying and cyberbullying, including a statewide survey of more than twenty-one thousand children in grades 3 through 12, and an annual regional survey of college freshmen (in 2010-11, we studied 617 freshman; during 201112, we studied another 616; to date this year, we've studied 293 more). ${ }^{1}$ We study some typical issues, such as how many kids report being bullied, and some unusual problems, such as kids who cyberbully themselves (yes, they do attack themselves), children who try to report bullying only to be told not to tattle, and the types of bullying that adults don't react to. I'll talk a lot more about the findings of this research program later in the book. (Appendix A has methodological details about the research cited in this book. Appendix B provides more information about MARC.)

But it's important that I don't only conduct research. I also do a great deal of work in the field with teachers, children, parents, administrators, and community members. MARC delivers programs, trainings, and services to teachers, students, and parents in hundreds of schools each year (during the 2010-11 school year, we visited about 250 schools). Along with other MARC faculty, I deliver, or supervise the delivery of, virtually every one of those services. I've written and tested two evidence-based curricula (a third is in progress), as well as the training materials for the college students we train to work with kids in dozens of schools every year. (You'd be amazed at what school-age kids will discuss with college students, whom they generally revere-it gives us wonderful insights.) I've also trained tens of thousands of teachers, administrators, and staff in hundreds of schools. Finally, I've spoken to and worked with parents' organizations in hundreds of communities. I think it's being heavily involved in both research and fieldwork that makes my perspective particularly useful. And because parents are such an important part of this mix, my additional perspective as a parent of three children makes my approach to the whole issue more realistic and grounded.

In addition to this combination of experiences, I'm something of a rare bird in that I'm interested in both child development and digital communications. I've been studying child development and aggression, and the difficulties that occur during childhood that result in violence or abuse, for more than twenty-five years. But my second area of interest - which, until about 2005, had absolutely nothing to do with my first — has always been the impact of technology on human beings and communications. These interests remained entirely separate until, a few years into the twenty-first century, digital communications began to consistently emerge as the newest and most insidious form of aggression on the planet (and a growing problem among children). Virtually overnight, my two areas of study merged.

Let me also introduce a few caveats. I'm not an attorney or a licensed therapist, and so won't be dispensing legal, clinical, or therapeutic advice in this book. Thank goodness.

\section{THE AGENDA}

The first thing I do, in chapter 1, is to summarize some of my research findings about patterns of behavior among bullies - in particular the emergence of "gateway behaviors" that are particularly difficult to monitor and assess at school. The chapter provides 
guidelines for assessing ambiguous behaviors and discusses why the dynamics of bullying become more fluid in the context of cyberspace.

Chapter 2 sorts through the wildly varying estimates of the prevalence of bullying. How common are these behaviors, really? Which children are most at risk? And what strategies can educators use to reduce risk and enhance resilience?

In chapter 3, we'll take a close look at the bullies themselves. In the past, bullies have tended to be children with low status and poor social skills, but today there is evidence that even popular children engage in bullying. The chapter discusses the impact of electronic devices on the development of children's social skills, and traces the plume of influence from electronic communications that colors so many social interactions between young people today.

In chapter 4 , the focus shifts to cyberbullying and how online behaviors influence (and typically exacerbate) in-person conflicts. We'll talk about some of the distinctiveand confounding - features of cyberbullying, and why it creates such a powerful sense of anxiety and helplessness among victims. In this chapter, I also outline some of the challenges in addressing online behaviors with tech-savvy kids.

In chapter 5, I go over new research findings about some of the unique problems that digital communications have brought us: sexting, self-cyberbullying, and other risky online behaviors from elementary school through high school.

Last but definitely not least, in chapters 6 through 8 I employ all these points to develop practical ways to address these issues - an area that is no less fraught than looking at the incidence and causes of bullying. What do we actually do in the moment, when we see these problems? Chapter 6 discusses the "9-second response" and other formal and informal approaches educators can use to address various kinds of bullying behavior. Chapter 7 draws on student surveys to suggest ways educators can empower bystanders and other peers to encourage prosocial behaviors and a positive environment. Finally, chapter 8 uses survey findings from parents to decipher their perspectives on bullying and cyberbullying, and uses that data to suggest tips for working effectively with parents.

\section{FRAMING THE ISSUES}

Before we start, let's discuss a few key points that are often not well understood, but can really help clarify everything that follows.

- First, the chronic overuse of the term bullying produces a set of problems that actually impede our prevention efforts.

- Second, bullying is an abuse behavior and needs to be understood as such.

- Third, bullying is not always so easy to recognize; teachers and administrators today sometimes struggle because they need better information about what to look for.

- Fourth, bullying in school is not separate from what happens on the Internet; we may tend to think of bullying and cyberbullying as distinct and unrelated events, but in actuality, they're neither. 
- Fifth, bullying is also not a problem that adults alone should fix; children do need to learn how to address meanness, all on their own.

- Finally, when it comes to educating children about their own social lives, we may need to rethink how we convey these messages.

\section{Overuse of the Word Bullying}

Bullying is a term that's being, well, bullied. It's been rendered essentially powerless by being constantly kicked around. The term is often used to describe any type of nastiness, or, even more commonly, virtually any situation that involves a meanspirited attack or hurt feelings. Accidents, fights, assaults, quarrels, malice, and differences of opinion are all mistakenly called "bullying" at times. The criterion for bullying isn't simply anything that hurts another person, although it's often confused for exactly that. Precisely defined, bullying is calculated, ongoing abuse that is aimed at a less powerful target. ${ }^{2}$ Certainly, a single incident of cruelty between two children can develop into bullying or abuse by becoming repetitive. Problems that happen between children of relatively equal power can also change and develop into a situation where one child predominates. What we should not do, however, is be too quick to label every onetime incident, and every equal-power fight, as bullying.

Why focus on the overuse of the term? Calling every sniffle a "cold" has no real impact; but calling every hurt "bullying" harms not only the targets and the bullies, but ultimately, all the people and the entire psychological climate in a school.

\section{Children can avoid responsibility}

One of the ways that bullying can be distinguished from other conflicts is that it's largely a one-way street when it comes to responsibility. The first problem with the overuse of the term, then, is that by permitting children to blithely frame many interpersonal difficulties as bullying, we're encouraging (or at least allowing) them to abandon any consideration of personal responsibility in situations where they may bear some. A child who has been fighting or victimizing others and knows that he or she will get some or all of the blame may be strongly tempted to assume the role of a victim of bullying and thereby avoid the penalty.

Let me emphasize (for those preparing to send me nasty e-mails) that I am absolutely not saying that children who are targets of bullies should take responsibility for their own victimization. ${ }^{3}$ What I am suggesting is that it's prudent to ask a few questions to help determine if a child is truly a victim of bullying before accepting that an abusive situation is happening. The desire to avoid responsibility for misbehaviors is completely normal, and trying to avoid punishment is one of the more understandable motivations for lying among children - who some experts estimate tell (on average) approximately one lie every ninety minutes by the age of six. ${ }^{4}$ But adults, eager to be advocates for a child's well-being, may hear the word bullying and abandon any meaningful investigation. Their emotional response (often predicated on their own childhood experiences) kicks them immediately into protective overdrive, in which gear few or no questions are asked. 
One could argue that children won't be motivated to call a situation bullying when it's not, because being a victim of bullying is a stigma. That may be true with peers, but when it comes to adults, using the term can actually be advantageous - it gets everyone's attention. Sometimes what they're really saying, as your blood pressure rises, is "I need you to sit up and take notice of what I'm telling you. This is important!"

\section{If everyone's a victim, then no one's a victim}

The second problem with overuse of the term is that by calling everything bullying, we greatly water down the very real and occasionally extreme distress that victims and targets of bullying experience. As a teacher, you've probably had your share of students and parents who pointedly identified even mild issues as bullying. But bullying isn't any old meanness that saunters down the sidewalk. Students who are subjected to bullying in school or online are not just living with perpetual fear; they feel unable to defend themselves, they endure wound after wound, yet they live in a world that doesn't defend them (or worse-doesn't even care to try). It's not just that the bully doesn't care-bullying can leave a victim with the sense that the world doesn't care.

It shouldn't be too much of a stretch, therefore, to realize that bullying can lead to learned helplessness, loss of motivation to try to learn, and loss of friends and support systems. For children who are vulnerable, the unremitting nature of this cruelty can contribute to depression and violence. ${ }^{5}$ Bullying appears, in some cases, to be a contributor to children committing suicide and homicide (particularly when children have other psychiatric risk factors). ${ }^{6}$ Such extreme consequences don't occur in most cases; but predicting which few children will react more severely is difficult and tricky.

The more commonplace (and less visible) reactions that victims experience in response to bullying are still important, yet risk being ignored when the term is used in situations characterized by little or no impact. Even when there is no outward manifestation of harm, being deliberately isolated and laughed at cruelly every single day can be devastating socially and academically, because the target must both endure the present and constantly dread the future, hovering like Damocles' sword. It's this unrelenting cruelty and the callous nature of such an environment that is watered down when we include every social slight or quarrel under the bullying rubric.

Even worse, the weakening of the term can mean that children themselves take bullying much less seriously. Watering down the seriousness of bullying is exactly the opposite of what we want - but we contribute to that diminution when we allow the overuse of the word.

\section{Bullying Is an Abuse Behavior}

Probably the single most common confusion I see in the field is the mix-up between bullying and fighting. Fighting or quarreling is an equal-power conflict. Bullying is an abuse behavior that, like all abuse behaviors, occurs between a powerful aggressor and a target who lacks the power to fight back. ${ }^{7}$ In fact, some researchers have argued that what we call "bullying" would be better described as "peer abuse." 8 Like all abuse victims, targets of bullying can behave in some very characteristic ways-for example, they may outwardly minimize bullying and refuse adult help, because their 
primary fear is retaliation. Few police officers today, called to a domestic abuse situation, would accept a beaten wife's reassurance that she is "just fine" and simply turn around and leave. We understand that an abused wife fears retaliation and so minimizes her distress; we understand that she's not saying that it's just fine to be beaten. Targets of bullying who tell adults "we're just goofing around" or "I don't mind, we're friends" may likewise be trying to minimize their own victimization. When adults attempt to mediate situations characterized by an imbalance of power, bullies and abusers who are succeeding in their dominance over their victim also show characteristic behaviors. They have a strong incentive to feign cooperation during a mediation, but this doesn't always mean that once out of sight, they'll truly comply. Understanding that bullying is an abuse behavior can be key in interpreting these reactions correctly.

\section{We Lack Information About Identification and Responses}

Many, if not most, of us saw or experienced bullying as a child, and it's natural that as adults we should be on the lookout for the kind of overt, often physical bullying behaviors that we saw when young. But a glance at newer data shows us that bullying today, in the majority of cases, does not involve any physical contact. ${ }^{9}$ My own studies, along with a number of others, show the overwhelming tendency to now use

psychological methods, including those I call gateway behaviors (more on this in chapter 2 ). The sensationalized cases we see on the news that involve physical torment are now the exception, not the rule. This mistaken focus on physical bullying sometimes causes us to miss the forest for the trees. We need to know much more accurately what to look for, and what to respond to.

Related to the issue of what to look for is the profound impact of the digital revolution upon the lives of children today. This constant digital communication is juxtaposed with what is actually a pretty low level of knowledge (and sometimes, maturity). Children may easily learn which buttons to push, but they often fail to understand the impact of electronic communications - despite their myriad and apparently effortless use of electronic devices. The fact is that digital devices change how we communicate, not just how often we communicate. I'll talk about this in the second half of the book in much more detail. For now, I'll content myself with pointing out that children easily absorb cognitive patterns that help them effortlessly use new technology; yet at the same time, they are less conscious of what information is missing in digital communications, and how the thinness of that interaction can contribute to social problems that are manifested both online and in school.

I think it's safe to say that both the growth in nonphysical bullying techniques and the proliferation of electronic communications have had an enormous impact on children and their bullying behaviors. The bad news is that we are only now-after more than a decade of ravenous digital consumption - beginning to understand these issues. But there is also good news. The data is clear and consistent about the kind of behaviors we need to look for in school. In addition, the struggle that children appear to be having with technology is not a technological issue per se. What children need from us is help in understanding how to send and interpret accurate communications. Estimating the impact of what you write (or post) is a skill related to life experience-happily, it's not a technical skill. 
You can't respond to bullying if you don't know what to look for. We all know how to respond to the more obvious, "old-fashioned" type of bullying: if we see children in a physical altercation, we pull them apart, investigate, and discipline accordingly. But what if the problem isn't so apparent? So far, the emphasis in bullying prevention has largely been on formal discipline. It's absolutely true that formal discipline plays a key role in responding to bullying. ${ }^{10}$ But how effective is it in preventing it? And if bullying isn't obvious, what role can discipline play? What kind of impact can formal school discipline have on cyberbullying? What actions can parents and educators take if they are not invoking formal discipline? Simply put, formal discipline alone is not enough of an answer. We cannot depend on it to address every need. In addition to discipline, we need to know what should precede it to help prevent both bullying and cyberbullying.

\section{Bullying and Cyberbullying-Neither Separate Nor Equal}

Because of the obvious ways that cyberbullying is separate from bullying, it can be challenging to see how they impact each other. But while adults tend to regard bullying and cyberbullying as two different and unrelated types of bullying, I found that they both occur as early as elementary school — and that they frequently become inextricably bound together by the time kids are in high school. ${ }^{11}$ To appreciate the interaction, though, it can be helpful to begin with the many ways that digital communication changes how we communicate and thus, in turn, changes the social interactions that ensue both online and offline. Kids don't see the school hallways and cyberspace as separate; for them, text messaging is just another way of talking, and the Internet is just another place where they see their friends. The profound impact that using technology has on cognitions and emotions is an area of knowledge that we're only just beginning to mine.

\section{Teaching Children to Address These Issues on Their Own}

Deciding when to react, and how not to overreact, to children's interactions - in person or online--can definitely be another challenge. On the one hand, it's clear that bullying and cyberbullying are behaviors we must address with children. On the other hand, it's an indisputable fact that occasional and mild mean behaviors are an inevitable part of life, and every child must learn to cope with such problems successfully. Actually, uncomfortable as it is, we want children to be exposed to mild meanness, because they must have practice in dealing with unpleasant people. We can always help children learn to cope with cruelty, but how can they do this if adults intervene in every incident, no matter how minor? If we accept that some things should be left to the kids to resolve, then what should trigger adult intervention? Every hurt feeling? Surely not. Seriously hurt feelings? Probably, but the nature of our intervention may depend on the circumstances. Repetitively hurt feelings? More likely. How can children learn to control these behaviors between themselves, if adults shoulder the entire responsibility for prevention? When mean behaviors are relatively mild, do we address the target, the 
aggressor, both, or neither? It's clear that adults have to correct antisocial behaviors, protect children from egregious harm, and help children cope emotionally when a peer is mean. But it can't just be about what we, the adults, need to do. We need to think about ways to empower kids to be co-leaders in addressing bullying and cyberbullying - and part of that strength must come from being an active part of the solution.

\section{Both the Message and the Messenger Matter}

Information doesn't occur in a vacuum, of course. The context of the message and the messenger help determine the relative impact of a communication. When issues are viewed by children as being of concern only to adults, and not to peers, the "gag factor" may enter into play (i.e., it may be more socially advantageous for children to disparage the message rather than to agree with it). Choosing a messenger with high status (i.e., one whose message is socially advantageous to adopt) can definitely increase effectiveness. Put more plainly, a high-status peer can influence values about social interactions better than the vast majority of adults. ${ }^{12}$

\section{Kids and the gag factor}

Many bullying prevention programs are probably more effective than children give them credit for; even programs that middle schoolers contemptuously dismiss may be planting seeds that bloom at some later point. But it's still true that the most effective anti-bullying messages are those that genuinely reflect children's and teens' perspectives and experiences. That's the reason that programs led by kids, for kids, are among the most successful. ${ }^{13}$ At the Massachusetts Aggression Reduction Center, we train graduate and undergraduate students to work with kids in grades $\mathrm{K}-12$ under the assumption that a message they bring will be more genuine and more powerful than that from any older adult-even the "coolest." However it's done, though, it's important to try to get past students' sense that adults do not understand, and cannot speak to, their life experiences.

There's no area where this is more important than when discussing digital life with kids. A cringe-worthy example is a well-intended, adult-led discussion about misusing e-mail (which most kids don't use with peers) or expressing puzzlement about the appeal of social networking. You might as well wear a blinking neon sign that reads, $I$ Don't Get It. Even when adults do "get it," having high-status peers deliver the message can endow it with more oomph.

\section{Misleading slogans}

Of course, ultimately the message matters as much (if not more) than the messenger. Most educators today have heard (and probably repeated) the mantra, "Tell an adult." I realize that this slogan is intended to be helpful, and sometimes it probably is; but I also see a number of significant problems with it. First, the word tell is a loaded word for children, with all of its implications of tattling. The slogan itself utterly fails to acknowledge the serious difficulty of violating one of the core tenets of childhood: never snitch. Another problem with this mantra is that it's been overused past the point of saturation. "If I hear 'tell an adult' one more time," an especially articulate seventh-grade 
boy once told me, "I'm going to throw up on the shoes of the self-righteous grown-up who says it."

Widely used slogans like this aren't just ineffective; if they simply didn't work, I wouldn't mind them so much. But their shorthand, catchall use can actually undermine more important prevention messages. Instead of asking children who witness bullying, "How can you help?" the "tell an adult" mantra, used in isolation, says to all bystanders, "Never mind helping. You can abdicate all responsibility here. Just pass the buck to the adults." The incredibly important role of other children may thus be actually undermined by the widespread adoption of such brief but catchy slogans. If we emphasize to students that adults are the answer, and that children themselves are not, and perhaps should not be involved in addressing bullying, then we've essentially told children that we don't expect them to hold much responsibility in their own community.

Finally, a third (pretty major) problem is that used in isolation, the Tell An Adult mantra implies that telling an adult, is a strategy that will succeed. According to recent research, that isn't necessarily true (more on this in chapter 7). ${ }^{14}$ It's painful to think, and to write, but I've seen too many cases of bullying to imagine that adults can always solve these problems for kids. I don't like feeling helpless. But honesty compels me to conclude that adults probably cannot always guarantee a resolution when children face such situations, and that makes me careful not to recommend only "telling an adult."

A similarly ubiquitous slogan is to "involve bystanders." But not all bullying episodes include bystanders. And when they do, are they the only peers who matter? What about the children who may not have actually witnessed bullying, but who knew about it, or who befriended (and thus empowered) a bully? What about the target's friends, or other friendly allies? The focus on bystanders doesn't always include them.

Of course, the idea that those who are physically present could actually stop or intervene in the bullying and report to adults is an appealing one. But although we tend to assume those strategies are helpful, recent hard data has made researchers question their actual success. This suggests to me that we may lack traction with this problem because we need to better understand the circumstances in which either intervening or reporting to adults actually helps with bullying situations. Although a great deal of the discussion about bullying prevention does emphasize just intervening or telling an adult, I think we need to understand more before we can truly and effectively empower those bystanders and peers.

\section{WHAT CAN THIS BOOK DO FOR YOU?}

This book is different because it needs to be. Let me begin by telling you what it won't do. It won't show you instant solutions, or one simple step that will always work. It won't turn you into an expert in social media. It can't make all adults - or all childrenbehave themselves. What this book will do, however, is be directly useful-offering perspectives that are concrete, grounded in research, up to date, practical, and realistic. ${ }^{15}$

One of the paradoxes I've discovered in working with educators is that our own childhood experiences with social cruelty can cause us to misdirect our responses to the bullying we see between students. Painful memories of being bullied may spur adults to seek simple, immediate solutions - but such a complex problem defies simplicity and takes time to solve. While I'm not going to review each and every potential theory, 
overall, the book should give the reader a good grasp on the complexity of the issue. With so many different facets, laying the entire problem at the door of a single factor can be tempting, but such an approach isn't likely to result in an effective response.

The pain of bullying is real, and pain always impels us to seek a rapid response. But changing a school climate isn't typically a fast operation, and social factors may work against us. For example, one type of bully today is a student who is popular and socially powerful. This fact often leaves students with the (sometimes correct) impression that being cruel is one way to increase social status. Because of the ingrained nature of this belief among kids, and because living with abusiveness leads to the general expectation that abusiveness and aggression are normal life circumstances, truly changing a school's psychological and social climate is, by necessity, something of a journey. I don't have any magic tricks to reveal, but the knowledge and behaviors that educators need to make a real difference can be found here. Expecting rapid, easy transformation is rarely if ever in the cards.

Ultimately, we can and should still expect to teach children that general civility is a centrally important social behavior. We hear a lot about respect, but I would argue that respect can be viewed as a positive sense of another person's value, a feeling you have inside of you for someone else. I don't see how we can require children to feel certain things. I do know, though, that we can require them to behave respectfully; that is, to adopt certain social manners that facilitate peaceful interactions and arrest hurtful behaviors. Requiring children to behave civilly, even if they don't like someone, does not mean that we don't care how they feel. It means that we're teaching them to care how other people feel.

But to teach kids successfully, we need to know what to look for; how to respond to it in a way that prevents both bullying and cyberbullying; how and when to wield formal discipline; and how to encourage appropriate assertiveness and self-efficacy in children while at the same time promoting those positive emotional connections with adults and peers that are so protective.

During the last twenty-five years, I've studied children, their social lives, their abusiveness toward each other, and the intersection between their face-to-face contact and their digital interactions. In making these studies, both anecdotally and in research, I've begun to better understand how to help others understand the phenomenon that we call bullying and cyberbullying. The goal of this book is to help you understand it too. Read on.

\footnotetext{
${ }^{1}$ E. Englander, Freshman Study 2011: Bullying and Cyberbullying, Research Reports from the Massachusetts Aggression Reduction Center (Bridgewater State University, June 2011), http://webhost.bridgew.edu/marc/research.html.

${ }^{2}$ U.S. Department of Education, "Bullying: Peer Abuse in Schools," LD Online, 1998, http://www.ldonline.org/article/6171/.

${ }^{3}$ A sobering report in the United Kingdom ("Teachers Tell Bullied Kids: Don't Be So Gay," Echo, November 5, 2011, http://www.echo-news.co.uk/news/local_news) found that bullied teens were told, far too often, that if they only "stopped acting gay" then the abuse would end. Statements such as these, which imply agreement with bullies ("it was justified"), place the blame and responsibility squarely on the victim, instead of
} 
supporting teens who may be seeking to establish their own identities. (It is important to note that well-intentioned adults who are unaware of the repercussions of their statements may at times say such things. It is a testament to the necessity of training adults who work with children.)

${ }^{4}$ J. Medina, "Kids Lie Every 90 Minutes-And That's a Good Thing," Huffington Post, January 15, 2011, http://www.huffingtonpost.com/john-medina-phd/kids-lie-every-90minutes b 807775.html.

${ }^{5}$ L. Bond et al., "Does Bullying Cause Emotional Problems? A Prospective Study of Young Teenagers," BMJ 323, no. 7311 (September 1, 2001): 480-484, doi:10.1136/bmj.323.7311.480; A. Brunstein Klomek et al., "Bullying, Depression, and Suicidality in Adolescents," Journal of the American Academy of Child \& Adolescent Psychiatry 46, no. 1 (January 2007): 40-49, doi:10.1097/01.chi.0000242237.84925.18. ${ }^{6} \mathrm{C}$. Winsper et al., "Involvement in Bullying and Suicide-Related Behavior at 11 Years: A Prospective Birth Cohort Study," Journal of the American Academy of Child \& Adolescent Psychiatry 51, no. 3 (March 2012): 271-282.e3. I am being deliberate with my language use here. The media, and many experts, have linked bullying victimization to the suicides of several children. I use the term possible because others have pointed out that it's difficult to assess the level and severity of many actual bullying cases (more on that later in the book) and it's typically the case that among suicide victims, multiple stressors are present (suggesting that bullying may not be the only cause of suicide). This is in no way intended to dismiss the very real trauma that abuse such as bullying can wreak upon its victims.

${ }^{7}$ E. Englander, "Spinning Our Wheels: Improving Our Ability to Respond to Bullying and Cyberbullying," Child and Adolescent Psychiatric Clinics of North America 21, no. 1 (January 2012): 43-55, doi:10.1016/j.chc.2011.08.013; D. Olweus, Aggression in the Schools: Bullies and Whipping Boys (Oxford, England: Hemisphere, 1978), http://psycnet.apa.org/psycinfo/1979-32242-000.

${ }^{9}$ Englander, "Spinning Our Wheels"; E. Englander, "Is Bullying a Junior Hate Crime? Implications for Interventions," American Behavioral Scientist 51, no. 2 (October 1, 2007): 205-212, doi:10.1177/0002764207306052; P. Gradinger, D. Strohmeier, and C. Spiel, "Traditional Bullying and Cyberbullying: Identification of Risk Groups for Adjustment Problems," Zeitschrift Für Psychologie/Journal of Psychology 217, no. 4 (2009): 205-213, doi:10.1027/0044-3409.217.4.205; M. McKenna, E. Hawk, J. Mullen, and M. Hertz, "Bullying Among Middle School and High School StudentsMassachusetts, 2009," Morbidity and Mortality Weekly Report (MMWR) 60, no. 15 (April 22, 2011): 465-471.

${ }^{10}$ D. Olweus, Bullying at School: What We Know and What We Can Do (Oxford, England: Blackwell, 1993).

${ }^{11}$ E. Englander, Study of 21,000 Children in Grades 3-12 in Massachusetts, Research Reports from the Massachusetts Aggression Reduction Center (Bridgewater State University, June 2011), http://webhost.bridgew.edu/marc/research.html.

${ }^{12}$ H. Cowie and R. Olafsson, "The Role of Peer Support in Helping the Victims of Bullying in a School with High Levels of Aggression," School Psychology International 21, no. 1 (February 1, 2000): 79-95, doi:10.1177/0143034300211006. 
${ }^{13}$ University of Wisconsin-Madison, At the Table: Making the Case for Youth in Decision-Making (Innovation Center for Community and Youth Development and National 4-H Council, 2003).

${ }^{14}$ S. Davis and C. Nixon, The Youth Voice Project (Penn State Erie, StopBullyingNow.Org, March 2010), http://www.youthvoiceproject.com/.

${ }^{15}$ For the sake of readability, and because this isn't a book for fellow researchers, the research findings I cite in the chapters don't include statistical or methodological details. Those can all be found in appendix A. All differences I cite in this book are statistically significant, with a few exceptions. Findings that approach significance but don't achieve the $p<.05$ standard are worded as "slightly different" or something similar. 


\section{Bullying Myths Exposed: Expert Elizabeth Kandel Englander Identifies the Most Effective Prevention and Responses for Bullying and Cyberbullying}

"Elizabeth Englander has written an essential book about bullying that every educator-and any parent thinking about how schools should handle this issue-should read. It's full of wisdom, practical advice, and original research, all of which reflect Englander's status as one of the foremost experts in the field." -Emily Bazelon, author of the national bestseller, STICKS AND STONES

"Bullying is a term that's being, well, bullied. It's been rendered essentially powerless by being constantly kicked around," writes nationally recognized bullying expert Elizabeth Kandel Englander. At the same time, bullying in schools and online is more pervasive than ever. It also has cruel and painful consequences as we hear about students taking their own lives in response.

In her practical and insightful book, BULLYING AND GYBERBULLYING: What Every Educator Needs to Know (Harvard Education Press; October 1, 2013), Englander draws on the most recent research, including her own original studies, to show educators how to flag problem behaviors - "gateway behaviors"and frame the most effective responses. She also examines the differences between face-to-face bullying and cyberbullying and places behaviors on a continuum to reveal how students themselves perceive their own and their peers' behavior and its consequences.

BULLYING AND CYBERBULLYING helps readers to:

- Distinguish the action of bullying from its impact

- Identify victims who are most at risk

- Apply methods to help children be more resilient and less vulnerable

Elizabeth Kandel Englander is a professor of psychology and the founder and director of the Massachusetts Aggression Reduction Center at Bridgewater State University, which delivers anti-violence and anti-bullying programs, resources, and research for the state of Massachusetts. She has written extensively for The New York Times and recently penned a thought-piece for CNN's Opinion on bystander interventions in bullying. In addition, Englander has received a lot of press in venues such as U.S. News E World Report, The Boston Globe, Fox 25 News at 10, and Sirius/XM's Doctor Radio.

Harvard Education Press, at the Harvard Graduate School of Education, publishes innovative, authoritative books covering critical issues in education.

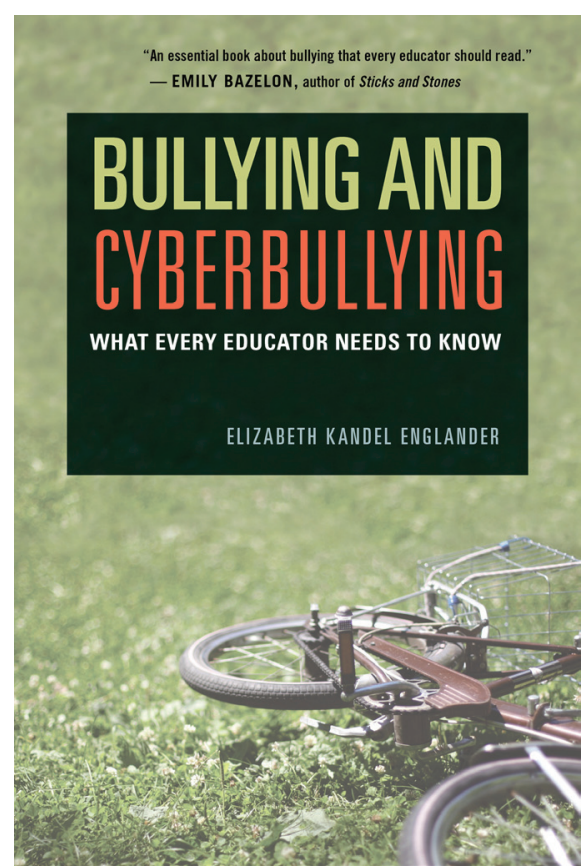

